\title{
Intensity of side effects of topical glaucoma medication and its influence on adherence behavior in patients with glaucoma
}

This article was published in the following Dove Press journal:

Clinical Ophthalmology

28 June 2014

Number of times this article has been viewed

\author{
Alice $L Y u^{\prime}$ \\ Stefanie Weise ${ }^{2}$ \\ Ulrich Welge-Lussen ${ }^{3}$ \\ 'Department of Ophthalmology, \\ Ludwig-Maximilians-University, \\ Munich, ${ }^{2}$ Department of \\ Ophthalmology, University of \\ Cologne, Cologne, ${ }^{3}$ Department of \\ Ophthalmology, Friedrich-Alexander- \\ University, Erlangen, Germany
}

Background: The aim of this study was to investigate the intensity of side effects that patients attribute to their topical glaucoma medication and their relationship to adherence behavior.

Methods: This was a questionnaire-based study of 123 glaucoma patients at a university eye clinic in Erlangen, Germany. An initial questionnaire asked about patient demographic data, the treatment plan, and intensity of side effects, and included Adherence to Refills and Medication Scale 2 (ARMS2) and visual analog scale (VAS-AD) scores. In a follow-up questionnaire, the treatment plan, intensity of side effects, ARMS2, and VAS-AD were reanalyzed.

Results: Most patients reported having few side effects, although only $20 \%$ said that they had no symptoms suggestive of side effects at all. The patients showed good adherence behavior on both the ARMS2 and VAS-AD scores, which were stable over time. The intensity of side effects experienced in the previous 7 days did not correlate with adherence scores and had no predictive value for adherence.

Conclusion: This study could not detect any significant influence of the subjectively experienced intensity of side effects on patients' adherence behavior. However, we believe that a simple and clear treatment plan with few side effects is still preferred by most patients.

Keywords: adherence, side effects, eye drops, glaucoma

\section{Introduction}

Primary open-angle glaucoma (POAG) is one of the leading causes of blindness throughout the world. ${ }^{1,2}$ It is a serious chronic disease of the optic nerve and is clinically associated with visual field defects that may eventually lead to blindness. However, most patients have no symptoms at initial presentation, since visual impairment usually occurs in the later stages of the disease. The major risk factor for POAG is elevated intraocular pressure (IOP), which is managed by medical or surgical intervention. Medical therapy for POAG requires ongoing use of IOP-lowering eye drops by the patient. Therefore, a major determinant of the success of medical therapy is the degree to which patients adhere with their glaucoma eye drops. Beside missing the scheduled dosing due to forgetfulness, there is also the deliberate choice of the patients to discontinue their therapy. This deliberate action of the patients to avoid or change their dose of medication can result from expected or experienced side effects from their prescribed medication. Side effects can eventually lead to complete cessation of therapy.

In general, side effects are underreported in clinical trials $\mathrm{s}^{3,4}$ and their intensity is often underestimated by both patients and doctors. Few studies have examined
Correspondence: Alice L Yu Ludwig-Maximilians-University, Department of Ophthalmology, Mathildenstrasse 8, 80336 Munich, Germany

Tel +49895I60 38II

Fax +498951605160

Email alice.yu@med.uni-muenchen.de 
the relationship between patients' adherence behavior and the symptoms or intensity of side effects experienced with glaucoma eye drops. In the research reported by Deokule et $\mathrm{al}^{5}$ approximately one third of glaucoma patients reported suffering from symptoms attributable to side effects of the medication. In contrast, Patel and Spaeth $^{6}$ did not find any significant correlation between symptoms of side effects and adherence behavior.

In this study, we first asked our patients about their treatment plan. The patients were then asked to report on the symptoms and the intensity of side effects that they attributed to their topical glaucoma medication. Further, we investigated the relationship between the subjectively experienced intensity of side effects and adherence behavior. Finally, these data were used to identify possible predictors of adherence in patients with glaucoma.

\section{Materials and methods Design}

This was a prospective study in which self-report questionnaires were distributed to patients with POAG at the university eye clinic, Friedrich-Alexander-University, Erlangen, Germany. The study was performed in accordance with the ethical standards laid down in the 1964 Declaration of Helsinki and approved by the local ethics committee. Patients gave their written informed consent before inclusion of their data in the study. The patients completed an initial questionnaire at the time of their first presentation to hospital (T1). This questionnaire asked about demographic data, the treatment plan, and the intensity of side effects, and included two measures of adherence, ie, the Adherence to Refills and Medication Scale 2 (ARMS2) and a visual analog scale for adherence (VAS-AD). Two months later (T2), the patients completed a second questionnaire at home, re-evaluating the treatment plan and intensity of side effects, along with ARMS2 and VAS-AD scores.

In total, 123 patients with POAG were included in the study. POAG was identified by an increase in IOP of $\geq 22 \mathrm{mmHg}$ measured by Goldmann applanation tonometry and by documented optic disk changes and/or visual field defects consistent with glaucoma. Inclusion criteria for the study were a diagnosis of POAG for more than 4 weeks and use of topical glaucoma medication for at least 4 weeks. The exclusion criteria were: other types of glaucoma (eg, congenital, closed-angle glaucoma, or secondary glaucoma), other eye diseases interfering with the management of glaucoma, a history of dementia or cognitive limitation, language barriers, and/or a reading and writing disability.

\section{Baseline demographic and clinical characteristics}

Demographic information, including: age, sex, living situation, school graduation, and work status, was collected in the first questionnaire. Clinical information was obtained from medical records, and included: time of diagnosis of glaucoma, current and maximal IOP measured by Goldmann applanation tonometry, best-corrected visual acuity using standardized acuity charts, slit-lamp biomicroscopy, gonioscopy, optic disk changes according to the Jonas classification, ${ }^{7}$ and visual field defect measured by white-on-white Humphrey 30-2 visual tests. The extent of visual field defect was assessed according to the Mills classification. ${ }^{8}$ Patients with progressive visual field defect had Goldmann perimetry and were classified as stage 5 by the Mills classification.

\section{Treatment plan}

The patients were asked a series of open-ended questions concerning: the name, number, and dosing regimen of their topical glaucoma medication, duration of treatment for glaucoma, number of visits made to their ophthalmologist, the presence of other chronic diseases, and regular concomitant medications. It was considered that this information would provide an insight into the complexity of the treatment plan.

\section{Intensity of side effects}

A questionnaire was developed to assess the intensity of side effects using the research reported by Rief et al. ${ }^{9}$ The patients were asked about 40 potential side effects of topical glaucoma medication as described in the literature. This included 30 systemic and ten local manifestations of side effects. The intensity of each side effect experienced in the previous 7 days was assessed using a four-point Likert scale with the answering options of "not present", "mild", "medium", or "strong". The patients were also asked whether or not they believed that these symptoms were caused by their glaucoma medication. A total score reflecting the intensity of side effects was calculated for all items.

\section{Adherence measures}

Patient adherence to their medication was evaluated by the ARMS Scale devised by Kripalani et $\mathrm{al}^{10}$ and covered two aspects of adherence, ie, correct refill of medication and correct intake of medication. In this study, we used a German-translated and adapted version (ARMS2) of the original version to measure adherence. The English original version had four items with prescription refill subscales and eight items with medication-taking subscales. The answers 
to the 12 items of the original version were arranged in a four-point Likert-scale with the possible answers "never", "sometimes", "mostly", and "always". In a ten-step numeric rating scale, "never" was represented by 0 and "always" by nine. Thus, all values above 0 reflected some degree of nonadherence. Slight nonadherence was scored as one and absolute nonadherence as 99 .

The VAS-AD was also used to measure adherence. The patients were asked to demonstrate on a scale ranging from "never" to "always", how often they took their eye drops correctly. The patients then set their answer on a $10 \mathrm{~cm}$ horizontal line, with $0 \mathrm{~cm}$ indicating "never" and $10 \mathrm{~cm}$ indicating "always".

\section{Statistical analysis}

The statistical analysis was done using PASW Statistics 18.0 (SPSS Inc., Chicago, IL, USA). Descriptive statistics were performed to obtain the mean values and standard deviations at T1 and T2. Bivariate correlations were performed to analyze dependent and independent variables. Regression models were used to assess the predictability of the independent variables of adherence. $P<0.05$ was defined as being statistically significant.

\section{Results}

\section{Basic demographic and clinical characteristics}

The study included 123 patients, comprising 78 females (63.4\%) and 45 males (36.6\%). The mean patient age was $67.0 \pm 13.7$ (45-88) years. The majority of patients lived with a partner $(n=90,73.8 \%)$ and were retired $(n=86,70.5 \%)$. Most had a general secondary school certificate $(n=67$, $54.9 \%)$ or a high school diploma $(n=31,25.4 \%)$. Concerning clinical characteristics, the better eye had a mean IOP of $13.4 \pm 3.1 \mathrm{mmHg}$ and a visual acuity of $0.8 \pm 0.2$. In comparison, the worst eye had a mean IOP of $15.6 \pm 3.8 \mathrm{mmHg}$ and a visual acuity of $0.5 \pm 0.3$. Six patients $(4.9 \%)$ were blind in one eye. In the better eye, the majority of patients had a stage 1 visual field defect according to the Mills classification and stage 2 optic disk changes according to the Jonas classification. In the worst eye, most patients had a stage 1 or 2 visual field defect according to the Mills classification and stage 4 optic disk changes according to the Jonas classification.

\section{Treatment plan}

To assess the complexity of the treatment plan, the patients were asked about the daily dosing regimen for their topical
Table I Values for treatment plan variables

\begin{tabular}{lllll}
\hline & pv & N & M & SD \\
\hline Appointments in I2 months & I-6 & 123 & 3.25 & 0.91 \\
Daily doses of eye drops & $>0$ & 123 & 3.0 & 1.37 \\
Duration of therapy in years & $>0$ & 121 & 10.85 & 9.70 \\
\hline
\end{tabular}

Notes: Appointments in 12 months: I, never; 2, I-3 times; 3, 4-6 times; 4, 7-9 times; 5, 10-12 times; $6,>12$ times.

Abbreviations: pv, possible values; $M$, mean value; SD, standard deviation.

glaucoma medication. On average, the patients required $3.0 \pm 1.4$ instillations of eye drops per day (Table 1). A quarter of the patients had to apply eye drops four times or more on a daily basis. The mean duration of glaucoma treatment at T1 was $10.9 \pm 9.7$ years. The average number of ophthalmology visits in the previous 12 months was $3.3 \pm 0.9$. More than half of the patients reported that they had visited their ophthalmologist 4-6 times in the previous 12 months, and $28 \%$ of the patients saw their ophthalmologist more often. Sixty percent of patients reported having at least one further chronic disease, and $86.8 \%$ were taking medication other than eye drops on a regular basis.

\section{Intensity of side effects}

The mean value for intensity of side effects was $6.5 \pm 8.1$ at $\mathrm{T} 1$ and $5.9 \pm 8.7$ at $\mathrm{T} 2$ (Table 2). These scores were in the lower range of possible values $(0-120)$. Most patients assessed the intensity of their side effects from glaucoma eye drops to be in the lower range, with the majority believing that few systemic side effects could actually be attributed to topical eye drops. However, only $20 \%$ of patients reported no symptoms of side effects at all. The maximal value for intensity of side effects was 38 at T1 and 37 at T2. Comparison of mean values between $\mathrm{T} 1$ and $\mathrm{T} 2$ did not show any significant difference $(t=0.40 ; d f=101 ; P=0.689)$.

The mean number of side effects experienced in the previous 7 days was four at both $\mathrm{T} 1$ and $\mathrm{T} 2$. As expected, these symptoms were mostly local, such as red eyes, pain, and visual disturbances. The most common systemic side effects attributed to eye drops were headaches and dizziness. The side effects reported at $\mathrm{T} 1$ and $\mathrm{T} 2$ are shown in Figure 1.

Table 2 Descriptive values of intensity of side effects at TI and $\mathrm{T} 2$

\begin{tabular}{|c|c|c|c|c|c|c|}
\hline & \multirow[t]{2}{*}{ pv } & \multirow[t]{2}{*}{$\mathbf{N}$} & \multicolumn{2}{|l|}{ TI } & \multicolumn{2}{|l|}{ T2 } \\
\hline & & & $\bar{M}$ & $\overline{(S D)}$ & $\bar{M}$ & (SD) \\
\hline Intensity of side effects & $0-120$ & 108 & 6.46 & $(8.12)$ & 5.94 & $(8.70)$ \\
\hline
\end{tabular}

Abbreviations: $p v$, possible values; $M$, mean value; $S D$, standard deviation; $T I$, time of initial presentation to hospital; T2, 2 months later. 


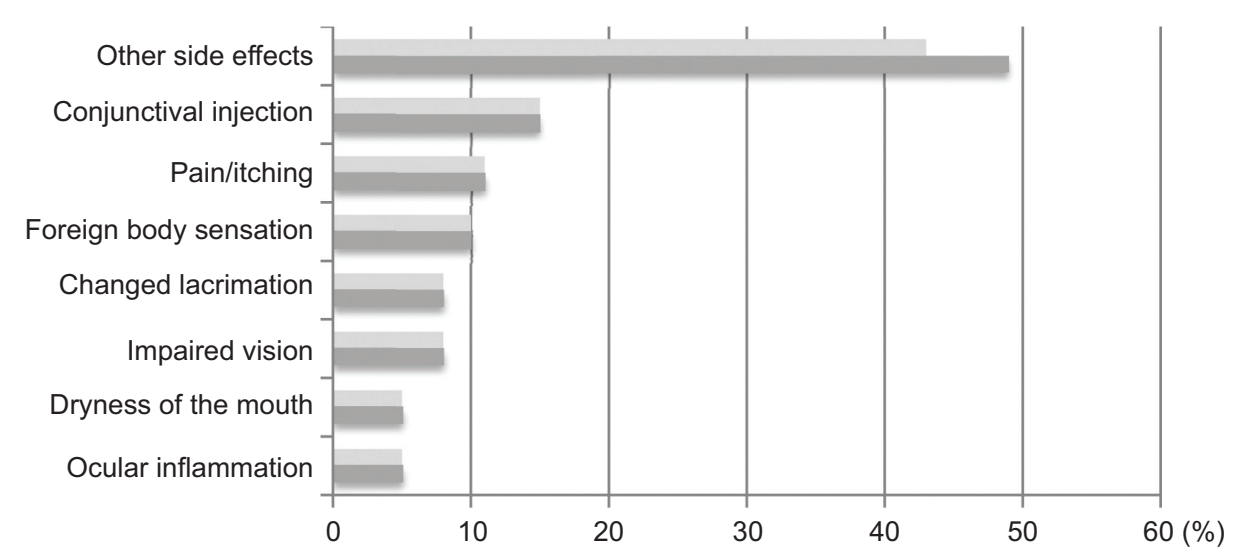

Figure I Percentage of side effects reported at time of initial presentation to hospital and 2 months later.

\section{Adherence to medicines}

The ARMS2 and VAS-AD adherence scores showed a good correlation between $\mathrm{T} 1$ and $\mathrm{T} 2$. The mean ARMS2 score was 3.38 at $\mathrm{T} 1$ and 2.8 at $\mathrm{T} 2$, and scores were stable over time ( $t=0.97 ; d f=118 ; P=0.335$ ). The descriptive values for VAS-AD were 9.03 at $\mathrm{T} 1$ and 9.08 at $\mathrm{T} 2$, and they were also stable over time $(t=0.34 ; d f=111 ; P=0.735)$. At $\mathrm{T} 1,18.5 \%$ of patients reported that they always used their eye drops correctly, and $68.9 \%$ reported correct use on at least $90 \%$ of occasions.

\section{Correlation between treatment plans and adherence}

The descriptive values for the treatment plan showed a weak correlation with ARMS2 and VAS-AD adherence scores at $\mathrm{T} 1$ and T2. Only a higher number of eye doctor visits was associated with a lower rate of nonadherence. A longer duration of glaucoma treatment was associated with a higher nonadherence rate (Table 3 ).

\section{Correlation between intensity of side effects and adherence}

The intensity of side effects experienced in the previous 7 days did not correlate with ARMS2 or VAS-AD adherence scores at $\mathrm{T} 1$ or at $\mathrm{T} 2$ (Table 4 ). To predict the adherence rate according to intensity of side effects, linear regression analyses were conducted with intensity of side effects at $\mathrm{T} 1$ as the predictor variable and ARMS2 or VAS-AD score at T2 as the dependent variable. Both models had a beta weight close to 0 and could not explain any part of the variance. Therefore, they did not represent valid prediction models for adherence. Multivariate regression analyses for the control variables were not included.

\section{Discussion}

Adherence behavior is a major determinant of the success of treatment for glaucoma. Various barriers to adherence have already been identified, and can be divided into the patientrelated factors, disease-related factors, and treatment-related factors. While patient-related and disease-related factors are mostly constant and difficult to overcome, treatment-related factors may be influenced by both the patient and the doctor. Important issues with regard to treatment-related factors are the presence and intensity of side effects from the prescribed medication. There is strong evidence that experiencing side effects is one of the main reasons for interruption of therapy.

Until now, no significant correlations between side effects and adherence behavior have been clearly detected. ${ }^{11}$ In this study, most of our patients described a low intensity of side

Table 3 Correlations between treatment plan variables and adherence

\begin{tabular}{|c|c|c|c|c|}
\hline & \multicolumn{2}{|l|}{ TI } & \multicolumn{2}{|l|}{ T2 } \\
\hline & ARMS2 & $\overline{\text { VAS-AD }}$ & ARMS2 & VAS-AD \\
\hline Systemic disease & -0.05 & 0.06 & -0.01 & -0.02 \\
\hline Appointments in 12 months & $-0.15 *$ & -0.08 & -0.02 & -0.04 \\
\hline Daily doses of eye drops & -0.12 & 0.06 & -0.06 & -0.05 \\
\hline Duration of therapy in years & -0.02 & -0.05 & 0.01 & $-0.23 * *$ \\
\hline
\end{tabular}

Notes: $* * P<0.01$ and $* P<0.05$

Abbreviations: ARMS2, Adherence to Refills and Medication Scale 2; VAS-AD, visual analog scale for adherence; TI, time of initial presentation to hospital; T2, 2 months later. 
Table 4 Correlations between intensity of side effects and adherence

\begin{tabular}{llllll}
\hline & \multicolumn{1}{l}{ TI } & & \multicolumn{1}{l}{ T2 } \\
\cline { 2 - 3 } \cline { 5 - 6 } & ARMS2 & VAS-AD & & ARMS2 & VAS-AD \\
\hline ISE TI & 0.16 & -0.07 & & 0.01 & 0.13 \\
ISE T2 & & & 0.08 & 0.11 \\
\hline
\end{tabular}

Abbreviations: ISE, intensity of side effects; ARMS2, Adherence to Refills and Medication Scale 2; VAS-AD, visual analog scale for adherence; TI, time of initial presentation to hospital; T2, 2 months later.

effects attributed to topical glaucoma medication, with few patients blaming their eye drops for systemic symptoms. As expected, the major symptom interpreted as a side effect was local irritation. Only $20 \%$ of patients had no symptoms of side effects at all. Our study group included mainly elderly patients with glaucoma, who had been using glaucoma medication for more than 10 years. Most patients took multiple daily doses of eye drops. With an average number of 3.3 visits to their ophthalmologists in the previous 12 months, our patients were considered to be under relatively good medical supervision. Therefore, it is not surprising that the ARMS2 and VAS-AD scores indicated good patient adherence behavior at T1 and T2. This finding is consistent with that of Sleath et $\mathrm{al}^{12}$ who found a high medication adherence rate in patients with a long history of glaucoma. Sleath et $\mathrm{a}^{12}$ also reported that patients using two or more glaucoma medications tend to experience more difficulty with side effects than those on one medication for glaucoma. For these reasons, they suggested that simplifying the medication regimen to fewer glaucoma medications might help to improve adherence with medication. One option could be the use of a fixed combination of glaucoma medications, which may be associated with a lower incidence of ocular hyperemia than when the individual components of such combinations are used as monotherapies. ${ }^{13,14}$ This may further reduce patient discomfort and the intensity of any side effects experienced. In addition, other studies have shown that fewer visits to the ophthalmologist are associated with worse adherence to medication. ${ }^{15}$ Therefore, patients should receive clear education on the importance of regular specialist appointments.

It has been shown that the presence of systemic disease has a positive influence on adherence behavior. ${ }^{11}$ This observation can be explained by the fact that patients with systemic disease are already conscious of their disease and taking medication. Thus, they have less difficulty integrating their eye drops in an existing treatment plan. We could not find a significant influence of systemic disease on adherence behavior, which may be attributed to the fact that our glaucoma patients were relatively experienced users of glaucoma medication. Further, we could not detect a correlation between the intensity of side effects experienced in the previous 7 days and ARMS2 and VAS-AD adherence scores. Our results may be explained by the assumption that patients with side effects were more nonadherent. Therefore, the intensity of side effects did not further influence their adherence behavior. On the other hand, the presence of side effects demonstrated that the eye drops were actually taken and applied correctly. These contradictory relationships may be the reason why no clear correlation between intensity of side effects and adherence behavior was found. While the patient reports of side effects confirmed that the prescribed eye drops were being used, they could not predict whether the patients would continue to be adherent to medication in the future.

This study included only a small sample size, ie, 123 patients, so can only reflect trends in behavior. Further, use of self-report questionnaires risks an overestimation of adherence behavior. Patients tend to give socially acceptable answers in standardized questionnaires, and previous research has shown that adherence measured by electronic monitoring devices is lower than that indicated by patient self-reporting. ${ }^{16,17}$ However, the intensity of side effects can only be measured by self-report. A further limitation of this study was the close temporal relationship between the two questionnaires administered in the study. A 2-month period between $\mathrm{T} 1$ and $\mathrm{T} 2$ was chosen since many patients visit their eye doctor every 3 months and it was considered that the second questionnaire should ideally be completed independent of the scheduled appointments. Unfortunately, many patients reported having made an appointment with their eye doctor just after answering the second questionnaire.

In summary, the intensity of side effects could not predict adherence behavior, which is contrary to what we expected. However, it must be borne in mind that our study group included very experienced and motivated patients, who had already made a high number of visits to eye doctors during their long duration of glaucoma therapy. We still believe that a simple and clear treatment plan with few side effects is preferred by most patients. Eventually, it is the patient who ultimately decides whether or not to take the medication.

\section{Disclosure}

The data in this study comprise part of the medical thesis undertaken by Stefanie Weise at the medical school, of Friedrich-Alexander-University, Erlangen, Germany. No grants or funding were received in relation to this work. 
The authors have no financial or proprietary interest in any material or method used in this study.

\section{References}

1. Quigley HA. Number of people with glaucoma worldwide. $\mathrm{Br}$ J Ophthalmol. 1996;80:389-393.

2. Quigley HA, Broman AT. The number of people with glaucoma worldwide in 2010 and 2020. Br J Ophthalmol. 2006;90:262-267.

3. Ioannidis JP. Adverse events in randomized trials: neglected, restricted, distorted, and silenced. Arch Intern Med. 2009;69:1737-1739.

4. Pitrou I, Boutron I, Ahmad N, Ravaud P. Reporting of safety results in published reports of randomized controlled trials. Arch Intern Med. 2009;169:1756-1761.

5. Deokule S, Sadiq S, Shah S. Chronic open angle glaucoma: patient awareness of the nature of the disease, topical medication, compliance and the prevalence of systemic symptoms. Ophthalmic Physiol Opt. 2004;24:9-15.

6. Patel SC, Spaeth GL. Compliance in patients prescribed eyedrops for glaucoma. Ophthalmic Surg. 1995;26:233-236.

7. Jonas JB, Gusek GC, Naumann GOH. Die parapapilläre Region in Normal- und Glaukomaugen [The parapapillary region of normal and glaucoma eyes. I. Planimetric values of 312 glaucoma and 125 normal eyes]. Klin Monbl Augenheilkd. 1988;193:52-61. German.

8. Mills RP, Budenz DL, Lee PP, et al. Categorizing the stage of glaucoma from pre-diagnosis to end-stage disease. Am J Ophthalmol. 2006; $141: 24-30$
9. RiefW, Barsky AJ, Glombiewski JA, Nestoriuc Y, Glaesmer H, BraehlerE. Assessing general side effects in clinical trials: reference data from the general population. Pharmacoepidemiol Drug Saf. 2011;20:105-145.

10. Kripalani S, Risser J, Gatti ME, Jacobson TA. Development and evaluation of the Adherence to Refills and Medications Scale (ARMS) among low-literacy patients with chronic disease. Value Health. 2009;12:118-123.

11. Bloch S, Rosenthal AR, Friedman L, Caldarolla P. Patient compliance in glaucoma. Br J Ophthalmol. 1977;61:531-534.

12. Sleath B, Blalock SJ, Covert D, Skinner AC, Muir KW, Robin AL. Patient race, reported problems in using glaucoma medications, and adherence. ISRN Ophthalmol. 2012;2012:902819.

13. Aptel F, Cucherat M, Denis P. Efficacy and tolerability of prostaglandintimolol fixed combinations: a meta-analysis of randomized clinical trials. Eur J Ophthalmol. 2012;22:5-18.

14. Quaranta L, Biagioli E, Riva I, et al. Prostaglandin analogs and timololfixed versus unfixed combinations or monotherapy for open-angle glaucoma: a systematic review and meta-analysis. J Ocul Pharmacol Ther. 2013;29:382-389.

15. Gurwitz JH, Yeomans SM, Glynn RJ. Patient noncompliance in the managed care setting. The case of medical therapy for glaucoma. Med Care. 1998;36:357-369.

16. Kass MA, Meltzer DW, Gordon M. Compliance with topical pilocarpine treatment. Am J Ophthalmol. 1986;101:515-523.

17. Okeke CO, Quigley HA, Jampel HD, et al. Adherence with topical glaucoma medication monitored electronically the Travatan Dosing Aid study. Ophthalmology. 2009;116:191-199.
Clinical Ophthalmology

\section{Publish your work in this journal}

Clinical Ophthalmology is an international, peer-reviewed journal covering all subspecialties within ophthalmology. Key topics include: Optometry; Visual science; Pharmacology and drug therapy in eye diseases; Basic Sciences; Primary and Secondary eye care; Patient Safety and Quality of Care Improvements. This journal is indexed on Submit your manuscript here: http://www.dovepress.com/clinical-ophthalmology-journal

\section{Dovepress}

PubMed Central and CAS, and is the official journal of The Society of Clinical Ophthalmology (SCO). The manuscript management system is completely online and includes a very quick and fair peer-review system, which is all easy to use. Visit http://www.dovepress.com/ testimonials.php to read real quotes from published authors. 